\title{
Entre a história da história e a história da educação: o Colégio Pedro II e a resistência aos estudos sociais na década de 1970
}

Between history of historiography and history of education: Colégio Pedro II and the resistance to the social studies during the 1970 S

SANTOS, Beatriz Boclin Marques dos. O currículo da disciplina escolar história no Colégio Pedro II - a década de 1970 - entre a tradição acadêmica e a tradição pedagógica: a história e os estudos sociais. Rio de Janeiro: Mauad X; FAPERJ, 2011, 336 p.

\section{Patrícia Santos Hansen}

hansenwagner@gmail.com

Investigadora auxiliar - Marie Curie Fellow

Universidade de Lisboa

Alameda da Universidade

1649-013 - Lisboa

Portugal

Palavras-chave

Colégio Pedro II; Ensino de história; História da educação.

Keywords

Colégio Pedro II; History teaching; History of education. 
Há determinados temas da história da história no Brasil que a despeito de sua óbvia relevância não têm ainda suscitado suficientes esforços de investigação por parte dos historiadores brasileiros. Um bom exemplo é a supressão da disciplina história dos currículos escolares durante os anos 1970 quando, ao lado da geografia, foi "substituída" pelos estudos sociais por efeito da Lei 5.692 de $1971 .^{1}$

Este é o pano de fundo do livro de Beatriz Boclin Marques dos Santos que ao dedicar-se ao caso do Colégio Pedro II e investigar as razões que motivaram a resistência à implementação da lei naquela instituição, acaba por iluminar um processo bem mais complexo do que se poderia imaginar.

Os protestos de caráter corporativo e associados a uma identidade profissional como as manifestações da ANPUH, por exemplo, ou as resistências cotidianas e individuais de professores que não separaram prática e o engajamento político, são as faces mais conhecidas da resistência aos estudos sociais pelos professores de história.

A novidade da tese de Santos, contudo, é procurar demonstrar um outro tipo de resistência, resultante de longa tradição institucional e de um modelo organizacional específico, os quais fizeram do Colégio Pedro II uma "instituição sui generis". Isso é possível somente porque a autora opera com um referencial teórico proveniente dos estudos sócio-históricos do currículo, remetendo-se principalmente aos trabalhos de Ivor Goodson. É este o instrumental que serve de esteio à estratégia de utilizar um caso singular - a resistência edificada em 288 um colégio sui generis - para compreender o quadro mais amplo das dificuldades de implementação de uma alteração curricular profunda - a supressão de uma disciplina muito sensível ao contexto político como é o caso da história - por imposição legal.

O livro consiste na tese de doutorado defendida junto ao Programa de Pós- Graduação em Educação da Universidade Federal do Rio de Janeiro (UFRJ) em 2009 e baseia-se em pesquisa realizada no Núcleo de Documentação e Memória do Colégio Pedro II (Nudom) ao qual Santos está ligada profissionalmente. Além das fontes ali depositadas, a autora também recorre a entrevistas de história oral realizadas com ex-professores da instituição e com um dos membros do Conselho Federal de Educação à época do debate em torno da Lei 5692.

Infelizmente, e a despeito do interesse da tese, o livro tem problemas que merecem reflexão.

O maior deles é que a tese precisaria ter sido minuciosamente revista antes de sua publicação em livro. Uma revisão de texto e, principalmente, uma revisão de conteúdo pois os erros presentes nos capítulos 2 e 3 comprometem a credibilidade da autora e do argumento desenvolvido nos capítulos seguintes, melhor desenvolvidos.

A maioria dos erros diz respeito à história da historiografia e percebe-se claramente uma lacuna que é confirmada pela lista de referências bibliográficas.

\footnotetext{
${ }^{1}$ Alguns trabalhos se ocuparam do tema como a dissertação de mestrado de Selva Guimarães Fonseca publicada pela primeira vez em 1993, em sua 10a edição em 2008 e outros trabalhos mais recentes como as teses de doutorado de Helenice Ciampi e Maria do Carmo Martins publicadas respectivamente em 2000 e 2002.
} 
A quase totalidade dos textos utilizados pela autora para tratar das concepções de história vigentes, desde a fundação do Colégio Pedro II em 1837 a qual coincide com a própria constituição da história como disciplina escolar no Brasil, pertencem a um único livro: Estudos sobre a escrita da história (GUIMARÃES 2006). A esta lacuna podem ser atribuídos deslizes como, por exemplo, a associação da fórmula ciceroniana "história mestra da vida" à historiografia de fundo iluminista dos séculos XVIII e XIX (SANTOS 2011, p. 70-71).

Entretanto, provocam pior impressão os erros decorrentes da má leitura das fontes e da bibliografia ou do uso de informações de segunda e terceira mão que resultam em frases e parágrafos como:

$\mathrm{Na}$ elaboração dos livros didáticos, os catedráticos [do Pedro II] demonstravam a intenção de transformar a história estudada nas universidades, pesquisada pelos grandes historiadores, em uma história ensinada, cuja característica principal era justamente o aval da academia (SANTOS 2011, p. 68).

Referindo-se à década de 1880 quando ainda não havia universidades no Brasil, o grande historiador do período, Capistrano de Abreu, estava ligado ao Colégio e o que poderia ser tido muito imprecisamente como "aval da academia" ficava entre o Instituto Histórico e Geográfico Brasileiro e o próprio Colégio Pedro II.

Ou ainda: "Quanto ao enfoque na história interna, João Ribeiro afirmava que von Martius deu apenas indicações vagas e inexatas..." em seu livro Como se deve escrever a história do Brasil, porém foi ele o 'primeiro a escrever integralmente a nossa história segundo nova síntese' ". Logo em seguida afirma que os livros de João Ribeiro "retratam uma história serial e cronológica" (SANTOS 2011, p. 102). Note-se que a autora transforma em livro a tese de Martius publicada na Revista do IHGB, se contradiz sobre a principal inovação de João Ribeiro² e demonstra não saber do que se trata uma "história serial".

Também no que diz respeito à historiografia da educação há ausências significativas na bibliografia utilizada, embora não comprometam tanto o resultado.

Como já foi dito, a principal referência teórica da autora é o trabalho de Ivor Goodson, a quem dedica todo o primeiro capítulo: "As contribuições de Ivor Goodson para as pesquisas sócio-históricas do currículo". É esta escolha que ancora a demonstração de que o Colégio Pedro II não acatou o que a Lei 5.692/71 determinava, o que é amparado pela comprovação da permanência de programas de história e geografia separados e sustentado por depoimentos de professores. É também com base nos estudos curriculares que a autora argumenta que a

\footnotetext{
${ }^{2}$ Contraste-se com o trecho do autor ao qual Santos remete suas afirmações: "Do sentido em que se deve tratar a história interna, von Martius deu apenas indicações vagas e inexatas, mas caracterizou a multiplicidade de origens e de pontos de iniciação no vasto território; sem embargo da contestação de alguma crítica menos bem informada, fui o primeiro a escrever integralmente a nossa história segundo nova síntese. Ninguém, antes de mim, delineou os focos de irradiação da cultura e civilizamento do país; nenhum dos nossos historiadores e cronistas seguiu outro caminho que o da cronologia e da sucessão dos governadores, caminho seguro mas falso em um país cuja história se fazia ao mesmo tempo por múltiplos estímulos em diferentes pontos" (RIBEIRO 1957, p. 22-23).
} 
congregação do Colégio não o fez devido a uma forte tradição institucional que conferia aos seus professores uma posição muito particular, em especial aqueles que ocupavam as cátedras que também seriam extintas com a Lei.

Ao ampliar a concepção de currículo, entendido como produto de negociações que começam na formulação dos conteúdos prescritos e passam pelo que deles é feito no espaço escolar, em particular na sala de aula, ${ }^{3}$ o trabalho de Goodson embasa a estratégia de análise que toma por eixo o encontro de dois processos com tempos diferentes: o que começa com as discussões sobre a introdução dos Estudos Sociais no currículo escolar brasileiro durante a década de 1920 no âmbito da divulgação das ideias pedagógicas da educação nova e culmina com a prescrição dos Estudos Sociais pela política educacional dos militares; e aquele que corresponde a uma "tradição" (ou "cultura escolar") fortemente enraizada numa instituição que era até então um dos lugares privilegiados de produção e prescrição da história como disciplina escolar. Daí a caracterização de um confronto "entre a tradição acadêmica e a tradição pedagógica", conforme o subtítulo do livro.

O conceito de "cultura escolar"4 merece aqui alguma atenção justamente por destacar a relativa autonomia dos espaços escolares em relação a fatores externos e a sua capacidade para gerar, segundo Antonio Viñao-Frago, "produtos culturais próprios" entre os quais as disciplinas escolares.

Nas palavras desse autor:

Ya sea que las disciplinas sean vistas como tradiciones o construcciones históricamente inventadas, como espacios de poder social y académico, como transmutaciones didácticas de saberes producidos fuera del mundo escolar, como saberes generados en el interior del mismo sin relación alguna o mínima con el exterior, o como organismos vivos que nacen, evolucionan y se transforman o desaparecen, el hecho es que llevan en sí mismas las marcas características de la cultura escolar. Son productos de ella (VIÑAO FRAGO 2008, p. 26).

É curioso que embora esteja de certa forma subjacente a todo o argumento desenvolvido, a autora não utilize explicitamente o conceito de cultura escolar que poderia ter sido útil e complementar a abordagem centrada na noção de currículo.

As poucas referências à cultura escolar (SANTOS 2011, p. 30) aparecem sem qualquer destaque e remetem aos desdobramentos de trabalhos que circularam no Brasil durante a década de 1980, os quais permitiram aos historiadores da educação brasileiros melhor "compreender os problemas da escolaridade com o olhar voltado para os mecanismos internos que compõem a organização escolar" (SANTOS 2010, p. 28).

\footnotetext{
${ }^{3}$ A historiografia da educação costuma utilizar a metáfora da "caixa preta" para referir-se à dificuldade de investigar o que ocorre nas salas de aula.

${ }_{4} \mathrm{O}$ conceito foi desenvolvido por autores como André Chervel, Jean-Claude Forquim, Antonio Viñao-Frago e Dominique Julia. É a versão deste último, contudo, cujo texto foi traduzido para o primeiro número da Revista brasileira de história da educação, que tem tido maior circulação no Brasil. A respeito das disciplinas escolares, diz Julia (2001): "não são nem uma vulgarização nem uma adaptação das ciências de referência, mas um produto específico da escola, que põe em vidência o caráter eminentemente criativo do sistema escolar". Sobre a fortuna do conceito de "cultura escolar" no campo da história da educação no Brasil conferir FARIA FILHO; GONÇALVES; VIDAL; PAULILO (2004).
} 
Nesse sentido, diz Santos, estes autores destacam que "no cotidiano da prática escolar, ocorre uma apropriação do currículo oficial pelos professores, por meio de processos de seleção de conteúdos que refletem a preponderância de determinados grupos no contexto escolar. Dessa forma, o currículo resultante de políticas públicas oficiais, ao ser implementado na escola, passa por uma recontextualização como resultado das especificidades da cultura escolar" (SANTOS 2010, p. 30).

Considerando o interesse do tema e da abordagem utilizada na tese, assim como os problemas identificados, permanece uma questão: Seria possível compreender a manutenção da disciplina história no currículo do Colégio Pedro II após sua extinção legal sem mobilizar o referencial teórico próprio à história da educação? Haveria como reconhecer os fatores-chave que permitiram uma tomada de posição institucional, para além das lealdades e interesses políticos dos vários agentes individuais que influem sobre os currículos entendidos como produtos de variados processos e negociações que só terminam na sala de aula?

Por outro lado, se esta é uma perspectiva possível para pensar o tema mais amplo das lutas em torno da manutenção da história como disciplina escolar frente aos estudos sociais nos anos 1970, há que identificar e compreender também outras forças e motivações. ${ }^{5}$ Porque se a história do ensino de história ou da história como disciplina escolar não prescinde do referencial da história da educação, em particular dos estudos sobre a história das disciplinas escolares, da formação docente, ${ }^{6}$ dos currículos e dos manuais, também é verdade que não pode prescindir da análise das relações que mantém com a disciplina de referência.

Portanto, o problema principal e mais frequente das investigações sobre a história ensinada (que não é exclusivo do trabalho aqui resenhado e afeta tanto os trabalhos provenientes dos programas de pós-graduação em história como em educação), parece estar afinal no escasso diálogo entre a história da historiografia e a história da educação no Brasil.

O quadro reflete a progressiva autonomia dos dois campos e o crescente distanciamento da historiografia da educação e da maioria dos seus pesquisadores das instituições formadoras de historiadores. ${ }^{7}$ Refletir sobre as razões disso é fundamental para poder construir uma ponte entre esses dois campos do conhecimento histórico e, consequentemente, para o avanço dos estudos sobre a história ensinada, ou seja, sobre seus currículos, sobre a formação de historiadores, sobre livros escolares, sobre práticas educativas.

Entretanto pergunto: não seriam estes estudos também essenciais para a compreensão das culturas e da consciência histórica? A resposta será positiva se tivermos em conta que a história ensinada é por princípio objeto da história da história e da história da educação.

\footnotetext{
${ }^{5}$ Vale dizer que a autora se refere de passagem ao posicionamento da ANPUH no período para o que remete a outra tese de doutorado em educação publicada em livro: A história prescrita e disciplinada nos currículos escolares: quem legitima esses saberes? (MARTINS 2002). Uma fonte interessantíssima sobre o assunto é o texto de Raquel Glezer publicado na RBH em 1982: "Estudos sociais: um problema contínuo".

${ }^{6}$ Sobre o impacto da Lei 5.692 na formação de historiadores cf. CIAMPI 2000.

7 Deve-se ressaltar nesse sentido o notável crescimento do campo da história da educação nas últimas décadas, além de uma certa tendência à circunscrição de sua produção aos centros de pesquisa e programas de pós-graduação em educação e aos seus próprios congressos, associações e publicações.
} 
O posicionamento da ANPUH contra a retirada da história dos currículos escolares e introdução dos estudos sociais na década de 1970 representou uma significativa resistência científica e política aquelas medidas que tinham grande repercussão sobre a formação de professores e, consequentemente, abalavam a identidade dos profissionais de história, implicando toda uma reorganização dos cursos universitários.

Em relação a isso, aliás, vale a pena ter em mente a importância de pensar as mudanças de paradigma na formação docente decorrentes da introdução de diferentes teorias e ideias pedagógicas ao longo do século XX, as quais alteraram radicalmente a formação de professores, incluindo obviamente a dos professores de história. Tais mudanças, tendendo para a valorização do saber pedagógico em detrimento dos conhecimentos da disciplina de referência, contribuiram para a construção de identidades profissionais específicas, distanciando o professor e o pesquisador de história.

Para complicar ainda mais, é fato que os historiadores "de métier" não têm, nunca tiveram e, muito provavelmente, nunca terão o monopólio da história. Nem por isso, contudo, o profissional de história pode abrir mão de compreender outros usos do passado.

No âmbito desta resenha essa observação serve para lembrar que naquilo que diz respeito à história da história ensinada, para além de considerar necessariamente outros aspectos que nela influem e respectivos pesos, cumpre não perder de vista as relações que sempre mantém com a disciplina de 292 referência. Todas estas questões complexificam o quadro da história da história. Porém, de maneira pertinente e saudável, em tempos de regulamentação da profissão de historiador, podem também estimular questionamentos muito atuais e uma reflexão fértil sobre identidades profissionais e fronteiras inter mas, principalmente, intradisciplinares.

\section{Referências bibliográficas}

CIAMPI, Helenice. A história pensada e ensinada: da geração das certezas à geração das incertezas. São Paulo: EDUC; FAPESP, 2000.

DELACROIX, C.; DOSSE, F.; GARCIA, P.; OFFENSTADT, N. (orgs.). Historiographies: I. Concepts et débats. Paris: Gallimard, 2010.

FARIA FILHO, L.; GONÇALVES, I.; VIDAL, D.; PAULILO, A. A cultura escolar como categoria de análise e como campo de investigação na história da educação brasileira. Educação e Pesquisa, São Paulo, v. 30, n. 1, p. 139-159, jan./abr. 2004.

GLEZER, Raquel. Estudos Sociais: um problema contínuo. Noticiário. Revista Brasileira de História, v. 2, n. 3, São Paulo, março de 1982, p. 117149. Disponível em: http://www.anpuh.org/revistabrasileira/view?ID_ REVISTA_BRASILEIRA $=37$

GUIMARÃES, Manoel Luiz Salgado (org.). Estudos sobre a escrita da história. Rio de Janeiro: Ed. 7 Letras, 2006. 
JULIA, Dominique. A cultura escolar como objecto histórico. Revista brasileira de história da educação, Campinas, n. 1, p. 9-43, jan./jun. 2001.

MARTINS, Maria do Carmo. A história prescrita e disciplinada nos currículos escolares: quem legitima esses saberes? São Paulo: EDUSF, 2002.

RIBEIRO, João. História do Brasil: curso Superior. 16a edição. Rio de Janeiro: Livraria São José, 1957.

SANTOS, Beatriz Boclin Marques dos. O currículo da disciplina escolar história no Colégio Pedro II - a década de 1970 - entre a tradição acadêmica e a tradição pedagógica: a história e os estudos sociais. Rio de Janeiro: Mauad X: FAPERJ, 2011.

VINÃO FRAGO, Antonio. La escuela y la escolaridad como objetos históricos. Facetas y problemas de la historia de la educación. História da educação, ASPHE/FaE/UFPel, Pelotas, v. 12, n. 25, p. 9-54, maio/ago. 2008. Disponível em: http://fae.ufpel.edu.br/asphe. 